\title{
Mediação informativo-cultural: e a formação dos mediadores?
}

\author{
Informative-cultural mediation: and the formation of mediators?
}

\author{
Marielle Barros de Moraes \\ Doutora em Ciência da Informação \\ Universidade Federal Fluminense \\ moraes.marielle@gmail.com
}

\begin{abstract}
Resumo
A mediação informativo-cultural vem se tornando cada vez mais pauta do dia nas pesquisas no âmbito das ciências da informação contemporâneas, principalmente, a partir do uso mais intenso das Tecnologias de Informação e de Comunicação (TIC) nos processos infocomunicacionais. Neste contexto, analisamos como está inserida a temática da mediação da informação e da cultura nos currículos dos cursos das Ciências da Informação na Iberoamérica. Os currículos (projetos pedagógicos e planos de ensino de disciplinas) utilizados como amostra foram aqueles de duas universidades cujos cursos da área de Ciência da Informação estão vinculados à Asociación de Educación e Investigación en Ciencia de la Información de Iberoamérica y el Caribe (EDICIC), quais sejam: o curso de Sistemas de Información y Documentación da Universidad de La Salle, da Colômbia, bem como os currículos dos cursos de Arquivologia, Biblioteconomia e Museologia da Universidade Federal de Minas Gerais, que se encontra na Região Sudeste do Brasil. A metodologia utilizada foi a Análise de Conteúdo, bem como a Análise Comparativa. Os resultados demonstraram que, nos textos dos projetos pedagógicos dos cursos analisados na área de Ciência da Informação do Brasil e da Colômbia, embora com algumas diferenças locais, a mediação é abordada de forma indireta, como algo que perpassa toda a atividade dos profissionais da informação, mas não é abordada especificamente como campo de reflexão próprio.
\end{abstract}

\section{Palavras-chave}

Ciências da Informação. Mediação da Informação. Mediação da Cultura. Formação em Ciências da Informação. Currículo.

\begin{abstract}
Information-cultural mediation has become an increasingly popular area of research in contemporary information sciences, mainly due to the more intense use of Information and Communication Technologies (ICT) in infocommunication processes. In this context, we analyze how the topic of mediation of information and culture is included in the curricula of the courses of Information Sciences in Latin America. The curricula (pedagogical projects and teaching plans of subjects) used as a sample were those of two universities whose courses in the area of Information Science are linked to the Association of Education and Research in Information Science in Latin America and the Caribbean (EDICIC) such as: the Information and Documentation Systems course at the University of La Salle, Colombia, as well as the curricula of the archivology, library and museology courses of the Federal University of Minas Gerais, located in the Southeast Region of Brazil. The methodology used was the Content Analysis, as well as the Comparative Analysis. The results showed that in the pedagogical projets texts of the courses analyzed in the area of Information Science in Brazil and Colombia, although with some local differences, mediation is approached indirectly, as something that pervades all the activity of information professionals, but is not specifically addressed as its own field of reflection.
\end{abstract}

\section{Keywords}

Information Sciences. Mediation of Information. Mediation of Culture. Education in Information Sciences. Curriculum. 


\section{INTRODUÇÃO}

As transformações pelas quais vem passando a sociedade contemporânea, principalmente, nos circuitos históricos das últimas décadas do Século XX e nas primeiras do Século XXI, possibilita que o sistema sociopolítico-econômico vivencie um processo de aceleradas e profundas mutações, associadas ao desenvolvimento e às rápidas inovações das ciências e das tecnologias, o que contribui, dentre outros, para a aproximação e a comunicação entre os povos e as culturas. Não por acaso, mediação vem, pari passu se tornando um conceito que funciona como senha de ingresso no contexto das mais diversas conversas não apenas dos estudiosos das ciências da informação e da comunicação, mas dos pesquisadores e profissionais de procedências intelectuais diversas. A mediação informativo-cultural vem se tornando cada vez mais pauta do dia nas pesquisas no âmbito das ciências da informação e da comunicação contemporâneas, sobretudo, a partir do uso mais intenso das Tecnologias de Informação e de Comunicação (TIC) nos processos infocomunicacionais.

Além da questão discursiva, também somos interpelados por signos, formas simbólicas que são postas em circulação para consumo, fato este que passou a ser intensificado quando houve o casamento bem sucedido das TIC com os meios de comunicação, o que vem modificando, sobremaneira, as culturas na contemporaneidade. Ou seja, elas transformaram e vem transformando o modo de pensar, de agir, comunicar, se apropriar de conhecimentos. Um das mudanças culturais trazidas pelas TIC concerne ao mundo do mercado, ou seja, compras são feitas on line, bem como a contratação de serviços, o controle das contas bancárias, a mobilidade urbana foi alterada com os aplicativos de taxis compartilhados e nossas transações financeiras pari passu vêm sendo realizadas de forma totalmente on line. Não à toa hoje um dos assuntos da ordem do dia é a tecnologia do Bitcoin, uma moeda que nasce totalmente virtual e que não possui representação física, tal como as moedas até hoje conhecidas. Além do Bitcoin, existem outras moedas, tais como: o litecoin, monero e dogecoin. Ela não é controlada por nenhum Banco Central ou casa de câmbio tradicional, o que gera bastante desconfiança na moeda, além do fato da mesma ser gerada de forma descentralizada, através de milhares de computadores que utilizam o poder computacional para realizar os cálculos. A rede trabalha para resolver uma série de problemas matemáticos, o que no fim leva à criação de um bitcoin, onde blockchain entra em ação. O blockchain trata-se de uma rede de blocos encadeados que armazenam com extrema segurança, pois são encriptados, todas as transações financeiras do bitcoin e outras criptomoedas. Assim, a Microsoft, IBM e outras grandes empresas de tecnologia têm suas próprias iniciativas e consórcios para financiar pesquisas e desenvolver soluções corporativas em blockchain. Portanto, no mundo tecnoinformacional contemporâneo é uma das áreas que, hoje, mais possui investimentos em pesquisas. Além do Blockchain há diversas outras tecnologias que estão na ordem do dia, alterando diversas culturas na contemporaneidade.

E é nesse contexto - onde as TIC passam a fazer parte das culturas contemporâneas de forma mais intensa, em que as culturas e a comunicação estão convergindo, em que os eleitores são sondados, consumidores testados, todos em larga escala no interior das redes sociais digitais, dentre outros acontecimentos infocomunicacionais - que a credibilidade dos mediadores é cada vez mais posta em suspensão. Não que nunca o tivesse sido, porém, com as redes sociais digitais se tornando um meio infocomunicacional cada vez mais presente no cotidiano das pessoas, a credibilidade dos mediadores é questionada e, às vezes, posta em xeque, numa escala nunca antes vivenciada. 
Se num primeiro momento, acreditava-se que a Internet poderia promover cada vez mais a democratização das sociedades, o livre fluxo de informação sem a presença indesejada dos mediadores, onde os cidadãos poderiam organizar seu próprio fluxo de informação; parece que esses fatos permaneceram como meras quimeras do período de ascensão da Internet e nos tornamos nós mesmos mercadorias dentro dos fluxos informacionais contemporâneos, fornecendo informações nossas a cada clique de computador, mas com a falsa sensação de que o acesso aos mais diversos sites de Internet é realizado de forma gratuita e impessoal, bastando ter acesso a um computador e a redes. No entanto, a ideia da desintermediação da informação, a qual fora proclamada a partir do advento da Internet, não passou de ilusão. Os mediadores, inclusive, ampliaram-se em número, mas com uma novidade: a sua capacidade de ser invisível. Queremos afirmar com isso que não é que a era da mediação tenha desaparecido, mas sim que ela se transformou, tornando a presença dos mediadores mais singela e sutil, ou para utilizar expressões do sociólogo polonês Zygmunt Bauman, se tornou mais líquida. A esse respeito, é desta forma que Parisier (2012, p. 57-58) se expressa:

O crítico Jon Pareles, do New York Times, diz que os anos 2000 foram a década da desintermediação. [...]. A história da desintermediação foi repetida centenas de vezes em blogs, artigos acadêmicos e programas de entrevistas. [...]. Então veio a internet e desintermediou as notícias. De repente, já não precisávamos confiar na interpretação que o Washington Post fazia de um comunicado de imprensa da Casa Branca- podíamos ler o documento por conta própria. O intermediário desapareceu- não só das notícias, mas também da música [...]. O futuro, diz essa história, é a era do contato direto. Porém, embora a submissão aos mediadores seja um problema real, a história da desintermediação tem uma boa dose de mitologia. Seu verdadeiro efeito é tornar os mediadores invisíveis.

Portanto, mesmo com os mediadores tendo a possibilidade de se tornar invisíveis, estes se tornaram cada vez mais importantes, pois nas vias infocomunicacionais, quem tem mais poder de disponibilizar uma quantidade enorme de dados e informações que chegam aos sujeitos de forma "desintermediada", possui também o poder de produzir o real. Ou seja, quem mais tem poder de aparecer nas redes sociais digitais, produz as informações que desejam e atingem o público que desejam. Não por acaso, vemos notícias sendo produzidas e divulgadas da forma como convém a determinados grupos midiáticos e determinados grupos de poder de forma, se não mentirosa, mas pelo menos enviesada para produzir determinadas sensações nos sujeitos e, assim, fazerem-nos comprar ou não determinada ideia ou produto. Uma vez que as redes sociais digitais são o lugar onde os sujeitos estão também participando da vida social global, o que propicia a transformação das culturas, os donos dos aparatos midiáticos possuem o poder de mediar as informações e produzirem-nas de acordo com seu público, por mais que seja a mesma notícia. Assim, liquidez, flexibilização, insegurança, incerteza, desencaixe passam a ser palavras de ordem que permeiam todos os aspectos da vida em sociedade, daí a necessidade de transformações nas estruturas das instituições sociais, principalmente daquelas que possuem por insumo básico a informação e o conhecimento, tais como arquivos, bibliotecas, escolas e museus, como forma de atender às novas demandas que se impõem.

Desta forma, torna-se necessário o desafio de decifrar a inserção dos conteúdos acerca de mediação da informação e da cultura nos currículos dos cursos de formação dos mediadores da informação e da cultura, a fim de que esses mediadores não deixem passar despercebido seu papel diante dos processos de mediação de informações e de culturas na 
sociedade contemporânea. Portanto, objetivamos analisar como está sendo realizada a inserção de conteúdos acerca de mediação da informação e da cultura nos currículos dos cursos das ciências da informação na Iberoamérica. Para alcançar os objetivos, passamos a delinear a metodologia. Em primeiro lugar, realizamos uma revisão de literatura sobre "mediação da informação", "mediação da cultura" e "formação em ciências da informação", apoiando-nos, principalmente, em autores latino-americanos e outros que foram utilizados como base teórica. Como são bastantes cursos na Iberoamérica, tivemos que retirar uma amostra representativa dos diversos casos de construção curricular existentes nesse espaço geográfico. Para tanto, a amostra utilizada foram os currículos (Projetos Político-Pedagógicos e planos de ensino de disciplina) de duas universidades cujos cursos da área de Ciência da Informação estão vinculados à Asociación de Educación e Investigación en Ciencia de la Información de Iberoamérica y el Caribe (EDICIC), quais sejam: o curso de Sistemas de Información y Documentación da Universidad de La Salle - Colômbia, bem como os currículos dos cursos de Arquivologia (dez anos de sua implementação em 2019), Biblioteconomia e Museologia da Universidade Federal de Minas Gerais no Brasil. As universidades foram selecionadas por possuírem os cursos da área de ciências da informação vinculadas à EDICIC e por se situarem na Iberoamérica, uma região onde a inserção das tecnologias, bem como as questões mediacionais encontram-se em um patamar de discussões e de usos similares. A metodologia utilizada foi a Análise de Conteúdo, conforme os postulados de Bardin (2004), bem como a Análise Comparativa.

\section{MEDIAÇÃO E CIÊNCIA DA INFORMAÇÃO: DISCUSSÃO DE UM CONCEITO}

Não é novidade saber que vivemos numa sociedade cada vez mais mediada pelos aparatos tecnológicos, tanto é verdade que uma das cenas mais cotidianas que vivenciamos são pessoas caminhando nas ruas, ou mesmo em seus locais de trabalho, etc. com seus Smartphones conectados à Internet que as põem em contato com diversas outras pessoas em quaisquer lugares do mundo. Assim, mediação se tornou senha de ingresso para as conversas do cotidiano, mesmo que ainda não se possua clareza acerca de sua conceitualização.

Mediação cultural, mediação científica, mediação social, mediação institucional, mediação profissional, mediação bibliotecária, mediação educacional, mediação da informação, dentre outros predicativos, são expressões que muitas vezes não se sabe ao certo o real significado desses conceitos e nem como eles atuam em nosso cotidiano; o certo é que, muito embora o conceito de mediação esteja cada vez mais em voga no mercado das ideias no mundo acadêmico contemporâneo e, principalmente, nas Ciências Sociais e nas Ciências da Informação, o seu conceito ainda não está bem definido.

$\mathrm{Na}$ área da Ciência da Informação, autores como Beluzzo, Santos e Almeida Júnior (2014, p. 66) afirmam que "A mediação da informação surge de um vácuo teórico do Serviço de Referência e Informação (SRI), principalmente, a partir de meados dos anos 1990 [...]", vácuo este que se deu, principalmente, a partir do advento do sistema Web e dos modernos sistemas informacionais, os quais, se acreditava, provocaria o fim da mediação e dos mediadores. Para os referidos autores, "A mediação da informação passa a ocupar esse vazio de concepções ou, melhor dizendo, inicia o processo de refletir sobre as ações desenvolvidas pelos equipamentos informacionais em seu relacionamento com seus usuários." Portanto, mediação surge no campo da Ciência da Informação como a necessidade de se teorizar cada vez mais sobre o Serviço de Referência e Informação (SRI) e em como se delinear as práticas de referência e de informação no âmbito da Biblioteconomia e da Ciência da Informação, 
principalmente, com o avanço das TIC no SRI, que passou a se chamar de Serviço de Referência e Informação Virtual. No entanto, essas pesquisas não pararam no campo da Biblioteconomia, mas vem adentrando a Arquivologia, uma vez há diversos autores desse campo analisando o conceito de Serviço de Referência em Arquivologia, a exemplo de Duff e Fox (2006).

Nesse contexto, as buscas passam a ser cada vez mais personalizadas e efetivas do que mesmo quando eram realizadas nos catálogos tradicionais das bibliotecas, o que possibilitou que os Serviços de Disseminação Seletiva da Informação passassem a ser realizados de acordo com usuários específicos. No entanto, a pergunta que nos fica: e quando a filtragem das informações se torna tão intensa a ponto de deixar diversas fontes de fora, não estaria o ambiente de informação enviesando as pesquisas que ali são feitas? Qual o papel de filtro dos mediadores? É ser específico ao máximo, ou mostrar outras possibilidades para os pesquisadores? As atividades de mediação, no âmbito dos ambientes de informação, não inseririam os pesquisadores numa "bolha de filtros", tal qual analisou Eli Parisier? Mas, o que é mediação no âmbito da Ciência da Informação?

Diversas são as tentativas de definir mediação. Um dos autores faz essa tentativa no âmbito da Ciência da Informação é Almeida Júnior (2015, p. 19), para quem:

[...] mediação da informação é toda ação de interferência - realizada pelo profissional da informação -, direta ou indireta; consciente ou inconsciente; individual ou coletiva; que propicia a apropriação de informação que satisfaça, plena ou parcialmente, uma necessidade informacional.

Portanto, conforme a conceitualização de Almeida Júnior (2015), as ações de mediação dos profissionais da informação não têm possibilidade de se dar de forma neutra, como durante muito tempo se acreditou acerca do fazer desses profissionais. Por sua vez, a apropriação de informações é o ato de tornar próprio, de tornar sua a informação que the foi mediada, não apenas de forma física, mas também o seu conteúdo, com vistas à ação dos sujeitos em sua vida, tanto no que concerne às significações, quanto às ressignificações dos conteúdos das comunicações. É neste viés que Martín-Barbero (1997) trabalha com o conceito de mediação que integra cultura e comunicação nos processos do cotidiano dos sujeitos. Portanto, se é a cultura quem interpela e faz comunicação e mediação, conforme os postulados de Veillette (2008), então aqui se encontra a impossibilidade de neutralidade dos mediadores, ou seja, eles possuem uma intencionalidade no seu fazer. Para o autor, é sempre a cultura que é interpelada como "mediadora" numa situação de conflito, e é ela quem serve de amortecedora dos confrontos, pois permite a circulação de discursos, valores e imaginários na sociedade. E, é nesse sentido, que Veillette (2008) afirma que "podemos dificilmente falar da intervenção de um mediador neutro e imparcial quando é precisamente a cultura quem interpela e faz mediação...". Neste viés, o argumento de neutralidade em relação aos mediadores é falacioso, sobretudo, aqueles mediadores que possuem como insumo básico do seu fazer os produtos culturais, tais como arquivistas, bibliotecários e museólogos, o que corrobora com a afirmação de Caune $(2014$, p. 2) quando relaciona cultura e mediação, afirmando que:

Se a cultura é um acontecimento social, não existe cultura a não ser manifestada, transmitida e vivenciada pelo indivíduo. A cultura existe, antes de mais nada, como herança e para compreendê-la devemos analisar os modos de transmissão desta, que é elemento constituinte da cultura. 
Em um artigo anterior, Caune (2000) já havia afirmado que a mediação cultural seria a construção do elo social, e dilata o conceito para a dimensão da história individual e coletiva, que religa os homens aos seus antepassados, por meio da sua cultura. Para o autor, a mediação deve ser vista entre dois eixos, o que ele denomina de horizontal, a saber, o das relações interpessoais, e o vertical, o que possui um significado mais transcendental. Assim, a mediação como um projeto social não pode se contentar em estabelecer laços efêmeros, mas deve participar na produção de sentidos que visem a engajar a coletividade. Nesse sentido, conforme a visão do próprio autor, o uso indiscriminado do conceito de mediação em todas as ciências e, inclusive, em alguns discursos do cotidiano, é sintomático de uma sociedade que tem medo de reconhecer conflitos e buscar espaços de diálogos. Se se usa de forma indiscriminada, então se torna este conceito tão fluido que pode levar não a construir laços, como afirmou Caune (2000), mas sim, a promover cada vez mais a ruptura dos laços sociais, pois os sujeitos passam não mais a dialogar (principalmente nas redes sociais digitais) sobre diferentes visões de um assunto, mas sim a se aproximar com quem mais pensa igual a ele e a deletar quem pensa diferente. Este fato efetiva o que analisou Jouët (1997) sobre as práticas de comunicação, ou seja, essas práticas, para a autora, se elaboram em torno de uma dupla mediação: a técnica (ferramentas, pois estruturam a prática) e a social (pois os meios de comunicação e de informação, bem como os seus usos e sentidos são abastecidos no corpo social e, portanto, depende da cultura de determinada sociedade e de como os filtros atuam nas redes sociais).

Por sua vez, Orozco Gómez (1994) fala não de uma dupla, mas de mediações múltiplas, afirmando que a interação TV-audiência emerge de um processo que é complexo, multidimensional e multidirecional e que ultrapassa a tela da TV. Para o autor, as fontes de mediação são os lugares onde se originam os processos que estruturam a recepção televisiva e são várias, tais como a cultura, política, classe social, gênero, faixa etária, etnia, instituições, movimentos sociais, etc. A multiplicidade das mediações é classificada por Orozco Gómez (1994) desta maneira: a) mediação individual: é a que se desenvolve a partir do sujeito membro de um contexto cultural concreto. b) mediação situacional: é a que tem como fonte a situação da interação, algo que vai além do momento com o contato direto com a TV, ou onde os membros de uma audiência interatuam usualmente, como na escola, bairro, trabaIho, etc. c) mediação institucional: as instituições realizam diversos recursos para implementar sua mediação, como poder, regras, condições materiais e espaciais, autoridade moral e acadêmica, etc. d) mediação tecnológica: parte do pressuposto de que os meios não apenas reproduzem as outras mediações, mas também produz a sua própria mediação. Embora a classificação tenha sido feita a partir de seus estudos sobre a TV, ela pode nos ser útil para refletir acerca de outras formas de comunicação, tais como as que são realizadas dentro dos diversos ambientes de mediação informativo-culturais, tais como escolas, museus, bibliotecas, arquivos, etc. Uma informação pode ser recebida de diferentes formas, a partir de diferentes meios, em diferentes locais, tendo a interferência de diferentes mediadores nesse processo.

Como a intervenção do mediador nos processos mediacionais, segundo Veillette (2008), não é uma intervenção neutra; então, assim como sugeriu Feuerstein (1980 apud BELLUZZO, SANTOS; ALMEIDA JÚNIOR, 2014, p. 67), o mediador é aquele que auxilia o educando/usuário na construção e escalonamento de seus estímulos, destacando vários critérios para a realização da mediação, classificando três deles como universais: a) intencionalidade e reciprocidade; b) significado e c) transcendência. Na sua perspectiva, a falta de mediadores com intencionalidade, que se coloquem entre o sujeito e o mundo, auxiliando-o em 
suas buscas e apropriações de informação provoca a alienação do sujeito da sua cultura. $E$ aqui reafirmamos a impossibilidade de uma atuação neutra dos profissionais da informação, haja vista que as atividades de seleção, organização e mediação da informação são impossíveis de ser realizadas de forma neutra, uma vez que toda seleção é seleção de alguma coisa que deixa de lado diversas outras, inclusive no mundo informativo-documental.

Tecendo um diálogo com Rendón Rojas (2013), este afirma que esse mundo informativo-documental surge do "ser informacional" da pessoa humana que, para existir, necessita criar, consumir, transformar, transmitir e conservar informação. Para o autor, nesse mundo informativo-documental se produz uma mediação, não como processo mecânico, instrumental que pode ser realizado por objetos: uma ponte, um computador, um programa - como afirma a teoria de Paul Rasse (2000), mas sim como um processo intencional entre os sujeitos, um processo comunicacional, uma interação mediada por símbolos, mas não só em nível sintático ou semântico, mas sim envolvendo o nível pragmático. Daí, também, a relação entre mediação e intencionalidade, como já afirmamos ao citar a teoria de Feuerstein. Por sua vez, Pirela Morillo (2006) afirma que no âmbito da produção de conhecimento e de sua recepção ativa e crítica, se dão múltiplas e complexas mediações, porque ocorrem no contexto de três dimensões: a) do emissor de primeira ordem, onde se dá a mediação; b) a do emissor de segunda ordem - profissional mediador e c) a do usuário, quem deve realizar uma recepção crítica e ativa.

O autor supracitado afirma que essas três dimensões da mediação só tem sentido, a partir da recepção crítica e ativa do usuário, que só é possível quando este é formado para o desenvolvimento da sua aprendizagem tecnológico-informativa e para sua inteligência investigativa e este fator produz uma quarta mediação, relacionada com o ensinar a usar a informação expressada em diversos meios, em outras palavras, é necessário ensinar ao usuário a dominar a informação em seu sentido mais amplo, e este ensinar ao usuário o uso da informação é um dos objetivos mais proeminentes do Serviço de Referência e Informação, ou seja, possibilitar ao usuário dos ambientes de mediação da informação o seu protagonismo diante do mundo infocomunicacional. O certo é que a formação na área das ciências da informação passou a se preocupar cada vez mais com o tema da mediação, a ponto de, muitas vezes, defini-la como objeto da Ciência da Informação, como chegou a sugerir Almeida Júnior (2009). Mas, como está inserido este conceito na formação em ciências da informação em alguns cursos da área da Iberoamérica? Os currículos dos cursos de ciências da informação estão discutindo esse conceito como teoria e prática de uma Ciência da Informação, ou ainda passa despercebido pelos construtores de currículo? Qual a importância de se pensar a mediação no interior dos currículos? E quando nesse território da atuação dos profissionais da informação se entrelaçam a cultura e as tecnologias, os currículos estão discutindo novas formas de atuação?

\section{MEDIAÇÃO E Formação EM CIÊNCIA DA INFORMAÇÃO: E OS CURRÍCULOS?}

O tema da mediação da informação na formação em Ciência da Informação pouco é explorado na literatura desse campo de conhecimento. Em pesquisa recente, Santos Neto e Almeida Júnior (2016) analisaram a inserção de disciplinas sobre mediação da informação nos currículos da área da Ciência da Informação no Brasil e obtiveram como resultados que, dos 77 cursos universitários que formam profissionais da informação no Brasil, os quais se encontram distribuídos em 48 escolas - sendo 17 com o curso de Arquivologia, 40 de Biblioteconomia, 2 de Ciência da Informação, 4 de Gestão da Informação e 14 de Museologia -, 
apenas 12 cursos possuem disciplinas que abordam a mediação da informação, ou em sua denominação ou em sua ementa, sendo que nesse levantamento, nenhum curso de Museologia apresentou uma disciplina que abordasse a temática da mediação.

Por sua vez, a mesma carência de abordagem desse assunto foi encontrada em pesquisa de Moraes (2017), pois o conceito de mediação pouco é explorado nos currículos dos cursos da área da Ciência da Informação no Brasil, tanto em seu texto escrito, quanto nos discursos de professores e de alunos. Quando os currículos abordam o conceito de mediação, referem-se muito mais ao que-fazer, às práticas profissionais, ou então à visão do filósofo Ortega y Gasset do bibliotecário como o filtro entre a informação e o usuário. Então, se no âmbito da formação dos profissionais da informação pouco se aborda o conceito e a prática de mediação, o que dizer então de um conceito que passou a circular no mercado das ideias dos bibliotecários denominado de desintermediação da informação?

E, aqui, retomo o diálogo com Parisier (2012) que analisou a história da desintermediação da informação e concluiu que essa história tem uma boa dose de mitologia, pois o que ela fez de fato foi tornar os mediadores invisíveis. E foi se aproveitando dessa invisibilidade dos mediadores causada, dentre outros motivos, pelo advento das novas tecnologias digitais, que voltou, por exemplo, a ideia do fim das bibliotecas, uma vez que tudo poderia ser digitalizado e encontrado num clique. No entanto, hoje se sabe que o volume de informações que pode ser encontrado na web é tão grande que há cada vez mais a necessidade dos mediadores atuarem como filtros entre as informações que são relevantes das que não são, bem como daquelas que são verdadeiras das que são criadas para confundir o leitor, as denominadas Fake News, Junk News e congêneres. E aqui algumas questões se tornam ordem do dia, quais sejam: não seria limitante recuperar informações muito precisas e deixar tantas outras de lado nas pesquisas dos usuários? Quando os serviços de alerta e a Disseminação Seletiva da Informação são disparados, não estariam invadindo a privacidade dos usuários?

Portanto, há cada vez a necessidade da inserção de disciplinas que se voltem a analisar as ações de mediação da informação nos currículos de formação dos profissionais da informação (entendidos aqui como arquivistas, bibliotecários e museólogos), pois, numa sociedade em que cada vez mais informações são produzidas e que a credibilidade dos mediadores é questionada, só um currículo que se preocupe com o pensamento crítico acerca do fazer dos mediadores em diversos ambientes de informação (arquivos, bibliotecas, museus) e, principalmente, nos setores de referência desses ambientes que essa situação pode vir a ser melhorada.

Mediação não é uma palavra da moda no mercado das ideias da Ciência da Informação, pelo contrário, ela é epistemologia e práxis da Ciência da Informação e, por este motivo, é necessário que os currículos insiram esta temática como práxis curricular.

\section{METODOLOGIA}

Em primeiro lugar, realizamos uma revisão de literatura sobre "mediação da informação", "mediação da cultura" e "formação em ciências da informação", apoiando-nos, principalmente, em autores latino-americanos como Martín-Barbero (1997), Orózco Gómez (1994), Almeida Júnior (2015), Pirela Morillo e Pulido Daza (2018) e outros. Em seguida, selecionamos a amostra a ser analisada, a saber, os currículos (projetos pedagógicos e planos de ensino de disciplina) dos cursos relacionados à Ciência da Informação, de duas universidades que estão vinculados à EDICIC, quais sejam: o curso de Sistemas de Información y Documen- 
tación da Universidad de La Salle - Colômbia (apoiando-nos nos estudos de Pirela Morillo e Pulido Daza (2018) e nos documentos originais - Projetos Político-Pedagógicos (PPP) encontrados na página web), bem como os currículos dos cursos de Arquivologia, Biblioteconomia e Museologia da Universidade Federal de Minas Gerais no Brasil (apoiando-nos nos estudos de Moraes (2017) e nos documentos originais - PPP encontrados na página web). As universidades foram selecionadas por possuírem os cursos da área de ciências da informação vinculadas à EDICIC e por se situarem na América Latina, uma região onde a inserção das tecnologias e as questões mediacionais encontram-se em um patamar de discussões e de usos similares.

A metodologia utilizada para análise dos dados foi a Análise de Conteúdo, conforme os postulados de Bardin (2011), bem como a Análise Comparativa entre os currículos da amostra utilizada. A forma da coleta de dados para a Análise de Conteúdo e para a Análise Comparativa deu-se buscando os PPP na página Web das universidades, bem como por comunicação via e-mail com os coordenadores e professores dos cursos. A Análise de Conteúdo é um método analítico que surgiu na década de 1930 nos Estados Unidos. Para Berelson (1954 apud BARDIN, 2011, p. 24), "É uma técnica de investigação que tem por finalidade a descrição objetiva, sistemática e quantitativa [mas também qualitativa] do conteúdo manifesto da comunicação [...]". Portanto, "[...] pode-se aplicar a uma grande diversidade de materiais, como permite abordar uma grande diversidade de objetos de investigação: atitudes, valores, representações, mentalidades, ideologias, etc." (LAVILLE; DIONNE, 1999, p. 214). Para a análise dos PPP, seguimos os passos propostos por Campos (2004), os quais adaptamos para esta pesquisa:

a) leitura flutuante dos PPP: em primeiro lugar, realizamos as leituras dos documentos curriculares e páginas web dos cursos selecionados, quais sejam: o curso de Sistemas de Información, Bibliotecología y Archivística da Universidad de La Salle - Colômbia, bem como os currículos dos cursos de Arquivologia, Biblioteconomia e Museologia da Universidade Federal de Minas Gerais (UFMG), para elaborar as categorias, já tomando por base o referencial teórico.

b) seleção das unidades de análise (as quais para o contexto desta pesquisa referemse às palavras/expressões: mediação, tecnologia, Information Literacy, alfabetização informacional, serviço de referência, serviço de informação), a fim de realizar a análise temática. Para essa análise são utilizados os objetivos do trabalho e algumas teorias como primeiros norteadores.

c) processo de categorização e de subcategorização. Essas categorias podem ser apriorísticas ou não apriorística. Apriorística: possui categorias pré-definidas (as que selecionamos são: mediação, Information Literacy, tecnologia, alfabetização informacional) e nãoapriorística: emergem totalmente do contexto das respostas dos sujeitos da pesquisa, o que, inicialmente, exige do pesquisador um intenso ir e vir ao material analisado e teorias embasadoras, além de não perder de vista o atendimento aos objetivos da pesquisa.

Os resultados desta investigação, apresentamos na seção a seguir, onde mesclamos em itálico, conteúdos do texto curricular de cada curso, com análises realizadas à luz da literatura de apoio.

\section{MEDIAÇÃO NOS CURRÍCULOS DA ÁREA DE CIÊNCIA DA INFORMAÇÃO IBEROAMERICA- NOS: ANÁLISES E DISCUSSÕES}

A opção pela análise dos conteúdos especificados nos PPPs e nas ementas das disciplinas pode soar, num primeiro momento, de forma redutora em relação às complexidades 
que envolvem a efetivação dos processos educacionais intra/extra sala de aula, relacionados a um curso de graduação. Sabemos que há uma distância entre essa formalização em documentos escritos e sua efetivação na realidade dinâmica e contraditória das salas de aula, ou seja, há uma distância entre o currículo prescrito e o currículo real das salas de aulas. Por outro lado, em que pesem essas considerações, esses documentos ainda assim se constituem no registro de concepções e prescrições relacionadas a determinadas visões dos campos científicos, de mundo dos atores curriculares, de sua transposição para os fazeres profissionais, de seu impacto na sociedade, e são determinantes para conformar atitudes docentes e discentes no processo de ensino e aprendizagem. Desse modo, sua análise, ainda que parcial (e que, por vezes, pode ser considerada enviesada), é inescapável diante dos objetivos desta pesquisa.

Para esta análise, foi utilizado o padrão itálico, preferencialmente, para destacar os textos originais dos documentos (PPPs/ementas), o que se tornou necessário para marcar as diferenças na textualidade do trabalho. Portanto, iniciaremos com as análises do currículo do curso de Sistemas de Información, Bibliotecología y Archivística da Universidad de La Salle, seguido pelas análises dos currículos dos cursos de Arquivologia, Biblioteconomia e Museologia da UFMG.

\subsection{Universidad de La Salle ${ }^{1}$}

O Curso de Sistemas de Información, Bibliotecología y Archivística da Universidad de La Salle surgiu como uma dependência da Facultad de Ciencias Economicas y Sociales e foi conquistando sua autonomia, iniciando as formações em 15 de março de 1971, com 22 alunos. O título expedido é o de Licenciado em Sistemas de Información, Bibliotecología y Archivística. O seu plano de estudos passou por dez modificações, a saber: 1971-1974; 1975 1978; 1979-1981; 1982-1992; 1993-1998; 1998-2002; 2002-2004; 2004-2008; 2009-2016; 2017. No entanto, foi em abril de 1998 que o curso de Bibliotecología y Archivística mudou seu nome para Programa de Sistemas de Información y Documentación, com ênfase especial em Pesquisa, Bibliotecología, Archivística e Administração, sendo que os conhecimentos relativos à TIC estão inseridos de maneira transversal. A opção por deixar marcado na titulação os nomes Archivística e Bibliotecología se deu como forma de possibilitar segurança jurídica para o exercício profissional, uma vez que as profissões de arquivista e bibliotecário são regidas por Lei na Colômbia, assim como no Brasil. A lei que reconhece a profissão de bibliotecário no território colombiano e regulamenta o seu exercício é a Lei $n^{\circ} 11$, de 1979 (COLOMBIA, 1979). Para atuar como bibliotecólogo é necessário: 1) o título de Licenciado em Bibliotecología, em escola ou faculdade, cujos programas de Bibliotecología tenham sido aprovados e igualmente reconhecidos pelo Estado; 2) quem obteve o título no exterior, em universidades de países que tenham com a Colômbia tratados internacionais vigentes, e seja reconhecido no Ministério da Educação da Colômbia; 3) quem obteve o título de Magíster ou Doctorado en Bibliotecología, outorgado por universidade colombiana ou estrangeira que reúnam as condições assinaladas nos incisos anteriores; 4) quem obteve o título em universidades estrangeiras de países com os quais não existiam tratados internacionais vigentes, poderão validar o título realizando um exame no Congreso Nacional de Bibliotecología e 5) quem, antes da vigência da Ley, tenham exercido cargos em bibliotecas e/ou programas de Bibliotecología, oficiais ou privados, por três anos ou mais, além de realizar um exame ante o Consejo Nacional de Bibliotecología. Para atuar como bibliotecário, é necessária a matrícula

\footnotetext{
${ }^{1}$ Os dados foram retirados do sítio web da instituição.
} 
no Consejo Nacional de Bibliotecología, o qual fiscaliza e controla o exercício da profissão. Por sua vez, a profissão de arquivista é regulamentada pela Ley $n=1409$, de 30 de agosto de 2010 (COLOMBIA, 2010), onde também consta o Código de Ética do arquivista. Para exercer legalmente a profissão de Arquivista na Colômbia, é necessária a formação acadêmica em Archivística, e sua inscrição no Registro Único Profesional de Archivistas e ter obtido a Carteira Profissional, expedida pelo Colegio Colombiano de Archivistas.

Em relação ao currículo do curso, este tem duração de dez semestres - cinco anos -, na modalidade presencial, e está sediado em Bogotá, capital do país. Seu Projeto PolíticoPedagógico reconhece como objeto de estudos o sistema formado pela interação de quatro elementos: a informação, o documento, o usuário e a instituição informativa-documental, ou seja, reconhece como objeto de estudos o sistema informativo-documental, conforme os estudos de Rendón Rojas (2013), um sistema que é formado pela inter-relação entre a informação, o documento, o usuário, o profissional da informação e a instituição informativadocumental.

O perfil do profissional a ser formado pelo curso de Sistemas de Información, Bibliotecología y Archivística é uma pessoa íntegra que promove o diálogo entre fé, ciência e culturas, com sentido crítico, valores e sensibilidade social, capaz de promover, desenvolver, gerenciar e liderar projetos em unidades, redes e serviços de informação bibliotecária, documental e arquivística que contribuam com a construção de nacionalidade e do desenvolvimento humano, econômico, social e com a proteção ao meio ambiente. Portanto, quando se visa a formar um profissional que tenha no diálogo a base do seu fazer, a ideia de mediação encontra-se explicitada. Além disso, é importante que sejam inseridas questões relacionadas à mediação no currículo uma vez que a essência do fazer dos profissionais da informação é a satisfação das necessidades informacionais dos sujeitos, dos usuários da instituição informativo-documental, e a essência do que-fazer do bibliotecário e do arquivista é o atendimento aos usuários em diversos tipos de serviços de referência e de informação. Por este motivo, o diálogo é essencial. O perfil desejado é de um profissional mediador entre fé, ciências e culturas, de maneira crítica e com alto sentido de responsabilidade social. Assim, o perfil desejado também é de um profissional que avalia e propõe alternativas de melhoria nos processos de geração, tratamento, transferência e uso da informação e da atividade científica, condizentes a satisfazer com pertinência e responsabilidade social as necessidades informacionais da comunidade. Outra característica do perfil do profissional desejado é de que o mesmo saiba orientar usuários e produtores de recursos e serviços de informação bibliográfica e documental em seu acesso e uso, observando a normas e as políticas adotadas, buscando ser coadjuvante no desenvolvimento integral da pessoa, do desenvolvimento da sociedade e do fomento à cultura.

Além da mediação social, a mediação tecnológica está inserida como uma das competências desejadas no profissional, uma vez que este utiliza tecnologias de informação e de comunicação como meio para otimizar a circulação dos recursos de informação através dos serviços e unidades de informação, contribuindo para a democratização do acesso à ciência, entendida como um componente central da cultura, e ao desfrute do patrimônio documental. Neste texto curricular, percebe-se que foram inseridos diferentes tipos de mediações, conforme analisado por Orozco Gómez (1993): TIC, a mediação tecnológica que também fora objeto de análise de Jouët (1997). Assim, diante deste contexto de uma sociedade informacional em que diversos signos são postos em circulação para apropriação e consumo, cada vez mais são necessários profissionais habilitados a ensinar o universo infocomunicacional aos sujeitos como forma de garantir a democracia nas sociedades. 
O currículo do Curso de Sistemas de Información, Bibliotecología y Archivística possui algumas disciplinas que podem nos levar à ideia de abordar a mediação: a) no segundo semestre: Fuentes y recursos de información; b) no terceiro semestre: Usuários, produtos y servicios de información; c) no quarto semestre: Servicios de Referencia; d) no nono semestre: Fomento a la lectura. e) no nono semestre: Gestión de Políticas Públicas de Información. Assim sendo, são um total de 5 disciplinas que abordam, de maneira direta (como no caso da disciplina de Servicios de Referencia) ou indireta, a questão da mediação; no entanto, não utiliza o termo em seu Projeto Pedagógico, nem em nomenclatura de disciplinas.

\subsection{Universidade Federal de Minas Gerais}

\subsubsection{Curso de Arquivologia}

O currículo do Curso de Arquivologia da UFMG é novo, oriundo do Programa de Reestruturação das Universidades Públicas (REUNI), e possui somente um PPP, que data de 2012. Em decorrência da forma de estruturação dos cursos da Escola de Ciência da Informação (ECI) da UFMG, a qual abrange os cursos de Arquivologia, Biblioteconomia e de Museologia, a partir de um núcleo comum, todos os professores da Escola são, potencialmente, professores de alguma disciplina para alunos de Arquivologia. À época da construção do currículo, o diretor da $\mathrm{ECl}$ era o professor Dr. Ricardo Rodrigues Barbosa. O currículo do curso possui tempo de integralização mínimo de 8 e máximo de 14 semestres e a primeira turma ingressou no primeiro semestre de 2009 , ou seja, este ano faz dez anos de implementação do curso. Vale ressaltar que a legislação que regulamenta a profissão do Arquivista no Brasil é a Lei Federal $n^{\circ}$ 6.546, de 4 de julho de 1978 (BRASIL, 1978).

O objetivo geral do curso é formar arquivistas aptos a atuar, de forma academicamente inovadora e socialmente comprometida com os valores do permanente desenvolvimento social e humano, e capazes de enfrentar, com habilidade e criatividade, as demandas de sua profissão, com competência técnica e relevância social. A partir do objetivo do curso, percebemos a intenção de formar arquivistas em diferentes vieses de mediação: social, humana e a técnica (aquela dos saberes-fazer da profissão).

O curso possui um Núcleo Comum com os cursos de Biblioteconomia e de Museologia da ECI/UFMG, contemplando os princípios da flexibilidade e da interdisciplinaridade, e é constituído por $960 \mathrm{~h}$, distribuído em dezessete atividades acadêmicas, a saber: Introdução à Biblioteconomia, Arquivologia e Museologia; Fundamentos de Organização da Informação; Informática Aplicada à Ciência da Informação; Cultura e Informação; Teorias da Organização; Fundamentos da Ciência da Informação; Gestão de Unidades de Informação; Introdução aos Bancos de Dados; Análise de Assunto; Linguagens de Indexação; Métodos e Técnicas de Pesquisa; Usuários da Informação; Memória e Patrimônio Cultural; Planejamento em Unidades e Sistemas de Informação; Bibliotecas, Arquivos e Museus Digitais; Preservação do Acervo; e Competência Informacional.

Por sua vez, o núcleo específico é composto pelas seguintes disciplinas: Fundamentos da Arquivologia; Organização e Métodos Aplicados à Arquivologia; Gestão de Documentos Arquivísticos; História Administrativa do Brasil e Regional; Avaliação de Documentos Arquivísticos; Gestão Arquivística de Documentos Eletrônicos; Arquivos Permanentes; Descrição de Documentos Arquivísticos; Planejamento e Gestão de Redes e Sistemas de Arquivo; e Diplomática e Tipologia Documental. 
Este currículo possui oito disciplinas, do total de trinta e uma, voltadas às questões mediacionais, quais sejam: Introdução à Informática, Cultura e Informação, Introdução a Banco de Dados, Memória e Patrimônio Cultural, Estudos de Usuários, Ação Cultural e Educação Patrimonial, Organização e Métodos Aplicados à Arquivologia e Elaboração de Projetos de Financiamento e Fomento. Ou seja, o currículo deste curso, a partir do lead da disciplina, parece abordar as questões mediacionais voltadas tanto no que diz respeito à midiatização, quanto do que-fazer do trabalho do arquivista. No entanto, não aborda em seu texto escrito, no currículo prescrito, os processos de desintermediação, ou seja, processos onde as mediações se tornam mais sutis e abstratas. Uma disciplina que cita diretamente o arquivista como mediador é a que se intitula Organização e Métodos Aplicados à Arquivologia, a qual aborda os conceitos básicos de O\&M e sua inserção no contexto dos arquivos, além de abordar o arquivista no âmbito das organizações: mediador estratégico do conhecimento. Assim, no âmbito das ementas das disciplinas foi a primeira vez que surgiu o termo mediação.

A disciplina de Introdução à Informática aborda a temática da forma como Rasse (2000) abordava o conceito de mediação, ou seja, como saber-fazer, como práticas profissionais e se trata de uma disciplina com apelo mais prático do que reflexivo e, mesmo abordando diretamente questões de midiatização, não se encontra nesta disciplina conteúdos referentes a algo mais reflexivo acerca das tecnologias na sociedade com vistas a formar um profissional crítico, ou de dar uma visão mais crítica às tecnologias, o mesmo ocorrendo com a disciplina de Introdução a Banco de Dados. Por outro lado, é sabido que cada professor transforma os currículos em sala de aula, delineando o currículo à sua forma de perceber a disciplina.

Já a disciplina de Cultura e Informação aborda as interrelações e dimensões material e simbólica, ou seja, que a mediação envolve a ideia de cultura, que se expressa tanto em sua forma material, quanto simbólica. Ela é o elo material e simbólico entre os homens.

Por sua vez, a disciplina de Memória e Patrimônio Cultural é outra disciplina que aborda diretamente em seu texto curricular a mediação da informação. O seu conteúdo aborda as interrelações entre memória e patrimônio cultural. Políticas públicas de patrimônio cultural no Brasil. A ação do Instituto Histórico e Geográfico Brasileiro. A atuação dos profissionais da informação nesse território da cultura é um grande espaço que ainda tem muito a se desbravar, tanto no que concerne ao patrimônio cultural mais tradicional, quanto ao que está ainda em formato de fluxos e que necessitam ser documentados e organizados para posterior acesso. Ou seja, há um vasto território ainda inexplorado no campo da cultura e do patrimônio tanto material, quanto imaterial que ainda não foi explorado como campo de atuação dos profissionais da informação, muito provavelmente porque ainda não se tem explicitado quem é esse profissional da informação, muito menos qual o seu campo de atuação em espaços não tradicionalmente ligado ao campo, tais como arquivos, bibliotecas e museus.

Por sua vez, outras disciplinas que contemplam a mediação em sua forma de saberfazer são as elencadas a seguir: Usuários da Informação a qual aborda os conceitos, evolução e tendências. Usuários e sistemas de informação. Ambientes de uso da informação. Modelos de comportamento informacional. Tipos de usuários e não usuários: características e necessidades. Metodologias de estudo de usos e usuário. Competência Informacional que estuda o movimento da competência informacional: conceitos, origem, evolução, influências. Competência informacional, leitura e letramento. Aprendizagem por meio da informação. Habilidades informacionais. Desenvolvimento de habilidades informacionais em diferentes contextos 
e suportes. Portanto, aborda mediação no sentido de Rasse (2000), como saber-fazer, como as práticas profissionais, inclusive no que concerne à introdução das tecnologias. Insere a disciplina de Usuários da Informação, a qual está diretamente ligada às questões presentes no Serviço de Referência e Informação das instituições.

\subsubsection{Curso de Biblioteconomia}

O atual PPP do Curso de Biblioteconomia da UFMG foi publicado no ano de 2008 e elaborado por uma Comissão Central de Reestruturação. O curso de Biblioteconomia da UFMG foi criado em sua modalidade de Bacharelado a partir de 25 de março de 1950 e, até o ano de 1990, passou por diversas sedes, até chegar no espaço onde até hoje se localiza. Reis, Xavier Junior e Pires (2012) afirmam que os primeiros locais onde o curso estava instalado foram: o Instituto de Educação de Belo Horizonte, no ano de 1950; na Associação Médica de Minas Gerais (1951) e também nas salas do Edifício Acaiaca, na Avenida Afonso Pena, no período de 1952-1953. No período de 1954-1963, o curso funcionou numa parte do porão do Colégio de Aplicação, da Faculdade de Filosofia, na Rua Carangola, e foi incorporado a então Universidade de Minas Gerais em 1966. O curso passou a ser reconhecido como uma Unidade da UFMG ainda em 1966, sob a denominação de Escola de Biblioteconomia. Deste modo, passou a funcionar no 6ㅇadar do prédio da Reitoria da Universidade onde permaneceu até 1972. Em 1983 ocupou uma das alas do antigo Colégio Universitário, juntamente com a Faculdade de Educação, transferindo-se depois para o terceiro andar do Prédio da Prefeitura da Universidade, atualmente Unidade Administrativa II, até a inauguração da sede atual, em 1990, antes denominada, Escola de Biblioteconomia e, atualmente, Escola de Ciência da Informação.

A profissão de bibliotecário no Brasil é regulamentada pela Lei № 4084, de 30 de junho de 1962, sendo o exercício da profissão de bibliotecário permitido apenas: a) aos Bacharéis em Biblioteconomia, portadores de diplomas expedidos por Escolas de Biblioteconomia de nível superior, oficiais, equiparadas, ou oficialmente reconhecidas; b) aos Bibliotecários portadores de diplomas de instituições estrangeiras que apresentem os seus diplomas revalidados no Brasil, de acordo com a legislação vigente. No Parágrafo único, afirma-se que não será permitido o exercício da profissão aos diplomados por escolas ou cursos cujos estudos hajam sido feitos através de correspondência, cursos intensivos, cursos de férias etc.

No currículo atual do curso de Biblioteconomia, afirma-se em relação à temática das tecnologias que o curso possui duas disciplinas, quais sejam: Introdução à Informática e Introdução a Banco de Dados, as quais se encontram no primeiro e no segundo semestre, respectivamente. Já no que concerne às disciplinas voltadas à mediação da informação, há seis disciplinas que contemplam os conteúdos referentes à mediação informativo-cultural, quais sejam: Cultura e Informação, Usuários da Informação, Memória e Patrimônio Cultural, Competência Informacional, Leitura e Formação do Leitor e Sistemas de Disseminação da Informação. Ou seja, disciplinas que mesclam o saber-fazer do profissional, com o refletir acerca do seu campo de atuação.

Na disciplina Cultura e Informação, os alunos refletem acerca das teorias da cultura. Cultura na sociedade contemporânea. A informação como base do processo cultural. As instituições de informação como agências de produção e transmissão cultural. Ação cultural do profissional da informação no processo de mudança social. Portanto, é uma disciplina que visa a que o profissional reflita acerca das teorias da cultura, de que a sua profissão tem por insumo básico a informação que também é cultura, é produto cultural. Na unidade dois, os 
alunos analisam a sociedade em rede, globalização e novas tecnologias da informação e comunicação. Informação, cultura e produção de conhecimento. Já na unidade três, os alunos refletem acerca da Biblioteca, informação e mediação cultural. Este é um dos poucos tópicos do currículo que trata diretamente do conceito de mediação, especificamente do conceito de mediação cultural, o que reflete que este conceito é pouco contemplado no âmbito deste currículo.

Já a disciplina de Usuários da Informação analisa os conceitos, evolução e tendências. Usuários e sistemas de informação. Ambientes de uso da informação. Modelos de comportamento informacional. Tipos de usuários e não usuários: características e necessidades. Metodologias de estudo de usos e usuário.

Outra disciplina que possibilita a formação de um bibliotecário mediador cultural é a que se denomina de Memória e Patrimônio Cultural. Esta disciplina aborda teorias, conceitos e ações metodológicas vinculadas ao estudo da memória e do patrimônio. Interrelações entre memória, patrimônio cultural e identidade. Políticas públicas de patrimônio e cultura no Brasil. Criação de instituições vinculadas à preservação da memória e do patrimônio ao longo dos séculos XIX e XX. Patrimônio imaterial e a inserção dos debates sobre memória e história afro-brasileira e indígena nas políticas culturais brasileiras. Sustentabilidade, educação ambiental e ações de preservação do patrimônio cultural. Esta disciplina está na interrelação entre a informação, a cultura e a mediação, conceitos esses inter-relacionados. Embora não cite diretamente que aborda a temática da mediação, ao tratar das questões da cultura aborda também as questões mediacionais, haja vista Veillette (2008) ter afirmado que é a cultura quem interpela e faz mediação, pois um objeto só se torna objeto cultural, se inserido num determinado contexto, com intencionalidade e significado para o ser humano. Daí, a relação intrínseca entre mediação e intencionalidade também analisada pelo autor.

Por fim, a última disciplina do currículo que aborda temáticas relacionadas à mediação é a que se denomina de Serviços de Disseminação da Informação, a qual aborda os serviços de informação em bibliotecas/unidades de informação públicas, escolares, universitárias, especializadas e comunitárias. Serviços de referência. Serviços de treinamento de usuários. Serviços de antecipação à demanda. Serviços de extensão e atividades culturais. Serviços de comutação bibliográfica. Projeto e avaliação de serviços e produtos de informação. Evolução e tendências atuais dos serviços de informação. Esta disciplina, além das outras já elencadas como do rol das que abordam a temática da mediação neste currículo, é a que congrega conhecimentos de todas as outras disciplinas relacionadas à mediação. Não apenas no quesito do saber-fazer, das práticas profissionais mais tradicionais, mas também, na formação de um bibliotecário que tenha como cerne da sua atuação a investigação. Ou seja, que as ações realizadas nos ambientes de mediação da informação no qual o bibliotecário atua sejam realizadas tendo como premissa básica a investigação antes das tomadas de decisão.

\subsubsection{Curso de Museologia}

O currículo do Curso de Museologia da UFMG (2009) também foi alterado depois dos concursos públicos que contrataram novos professores para a ECI/UFMG, especificamente, para o novo curso. Para a criação do curso de Museologia foi instituída uma Comissão de Planejamento e Desenvolvimento do Projeto Pedagógico do Curso de Museologia. Esta comissão foi formada pelos professores: Paulo da Terra Caldeira, Mônica Erichsen Nassif e Carlos Alberto Ávila Araújo, por meio da Portaria no 31/08, de 3 de setembro de 2008. No processo de criação do curso, foram estabelecidas parcerias com a Escola de Belas Artes (EBA) e 
com a Rede de Museus e Espaços de Ciência da UFMG. Em 2009, formalizou-se a participação da EBA no processo de criação do curso, incluindo os professores da EBA, Eliana Ribeiro Ambrosio, Marilene Corrêa Maia, Yacy-ara Froner e Willi de Barros Gonçalves, à comissão encarregada da elaboração do Projeto Pedagógico do Curso. A criação do curso foi autorizada pela Câmara de Graduação da UFMG, de 9 de junho de 2009, tendo o Curso de Museologia recebido sua primeira turma no segundo semestre de 2010. O curso foi regulamentado pela Portaria $\mathrm{n}^{\circ} 112$, de 14 de fevereiro de 2014, e em julho daquele ano, formou-se a primeira turma de museólogos da UFMG. Assim, analisamos o currículo que data de 2009.

O objetivo geral do curso é formar museólogos aptos a empreender estudos e a produzir conhecimentos que contribuam para o avanço do campo da museologia e capazes de atuar com responsabilidade social, ética e domínio articulado dos conhecimentos teóricos e aplicados da museologia em contextos patrimoniais e sociais distintos, especialmente em processos de intervenção em museus, centros de documentação e informação, centros culturais, serviços e redes de informação, órgãos de formulação de políticas e gestão do patrimônio cultural. Os conceitos de ética e de responsabilidade social mereceriam uma análise mais crítica acerca da forma como têm sido incorporados pelos currículos da área de Ciência da Informação, mas não caberia fazê-lo aqui. O que nos importa, nesse caso, é que este conceito é diretamente relacionado ao de mediação da informação, uma vez que esta busca a disseminação do diálogo, da coparticipação entre os diversos povos e culturas, conforme os conceitos de Orozco Gómez (1993) e suas múltiplas mediações, bem como de Jouët (1993), para quem a mediação é técnica, mas também social.

Da mesma forma dos currículos anteriormente analisados, também podemos perceber que não há uma disciplina voltada especificamente para o conceito de mediação. No entanto, há a disciplina de Usuários da Informação e a de Competência em Informação que, a depender do enfoque, podem se voltar a esses conhecimentos e ao próprio conceito de mediação como saber-fazer. Por outro lado, se tomarmos mediação como cultura, ou cultura como mediação, há disciplinas que contemplam essas questões no âmbito deste currículo, tais como a de: Cultura e Informação; Patrimônio Cultural do Mundo Moderno e Contemporâneo; Memória e Patrimônio Cultural; Patrimônio Cultural no Brasil e Patrimônio Cultural Mineiro. Além disso, se tomarmos mediação como o saber-fazer, como as práticas profissionais dos museólogos, então o número de disciplinas que abordam a temática se expande.

\section{CONCLUSÕES: PARA ONDE APONTAM OS VENTOS DA FORMAÇÃO EM CIÊNCIA DA IN- FORMAÇÃO?}

O mundo informacional está em constante transformação, a ponto de os currículos de formação universitários, muitas vezes, não conseguir alcançar a velocidade dessas transformações. No entanto, uma coisa é certa: as questões relacionadas à mediação e ao contato dos sujeitos uns com os outros sempre serão necessárias como forma de estarmos, de fato, vivendo em sociedade. O conceito de mediação inserido nos currículos e como práticas profissionais possibilitará cada vez mais que as profissões da informação não sejam vislumbradas como puramente técnicas e neutras, mas sim que a sua necessidade social seja cada vez mais visualizada pela sociedade, aproximando profissionais da informação e as mais diversas comunidades de forma a que as necessidades de informação dos grupos sociais sejam satisfeitas, o que possibilitará cada vez mais um maior reconhecimento dos profissionais da informação por parte da sociedade. 
Mediação informativo-cultural é um conceito que vai pari passu sendo cada vez mais analisado e desenvolvido no âmbito das ciências da informação na Iberoamérica, muitas vezes, tomando-o como objeto de estudos na área das ciências da informação, em detrimento do conceito de informação. No entanto, ainda carece de estudos que delineiem qual o perfil de mediador que a sociedade contemporânea necessita, haja vista que a visão de um mediador neutro, já é sabida a sua impossibilidade. Quando os currículos, como, por exemplo, os casos dos cursos da Universidade Federal de Minas Gerais (Brasil) e da Universidad de La Salle (Colômbia), pouco citam a mediação como horizonte de sua formação, é sinal de que a área ainda permanece na dualidade de visões entre o profissional da informação muito mais como um ordenador documental, e pouco dando atenção à sua visão como mediador informacional, ou mesmo como um educador para a informação.

Os resultados demonstraram que, nos textos dos PPPs dos cursos analisados na área de Ciência da Informação do Brasil e da Colômbia, embora com algumas diferenças locais, a mediação é abordada de forma indireta, como algo que perpassa toda a atividade dos profissionais da informação, mas não é abordada especificamente como campo de reflexão próprio. Não obstante, as pesquisas e publicações acerca de mediação vêm aumentando nos últimos anos na área da Ciência da Informação; por exemplo, um dos maiores eventos da área da Ciência da Informação no Brasil, o Encontro Nacional de Pesquisa em Ciência da Informação (ENANCIB) possui um Grupo de Trabalho para discutir especificamente as questões relativas à mediação, o GT-3: Mediação, Circulação e Apropriação da Informação. Quando os currículos abordam a temática da mediação e citam diretamente o termo, é mais vinculado aos aspectos práticos da profissão, incorporando a visão do mediador ser o facilitador entre a informação e o usuário, ao estilo Ortega y Gasset, bem como no que concerne às práticas e saberes fazer profissionais à Paul Rasse.

Neste estudo, concluímos que o conceito de mediação ainda não se apresenta como norteador da formação em ciências da informação no Brasil e na Colômbia, e que o conceito de mediação, embora possua potencial estratégico para criar modos alternativos de construção curricular, de atuação dos profissionais da informação, ainda se encontra pouco presente nos currículos analisados. Na ausência, ou na pouca clareza do conceito de mediação, o diálogo entre as áreas da informação no campo do currículo e mesmo nas práticas profissionais, numa perspectiva inter ou transdisciplinar, encontra dificuldades para se constituir evidenciando aspectos de sociedade e de ciência percebida pela Ciência da Informação. Além disso, embora os ventos teóricos e de práticas profissionais (na Colômbia) apontem para que a mediação seja o objeto da Ciência da Informação, este fato ainda não se consolidou nos currículos de formação dos profissionais mediadores de informação e de culturas.

\section{REFERÊNCIAS}

ALMEIDA JÚNIOR, O. F. Mediação da informação: um conceito atualizado. In: BORTOLIN, S.; SANTOS NETO, J. A., SILVA, R. J. (org.). Mediação oral da informação e da leitura. Londrina: ABECIN, 2015. Cap. 1, p. 9-32.

ALMEIDA JÚNIOR, O. F. Mediação da informação e múltiplas linguagens. Pesquisa Brasileira em Ciência da Informação, Brasília, v. 2, n. 1, p. 89-103, jan./dez.2009.

BARDIN, L. Análise de conteúdo. 3. ed. Lisboa: Edições 70, 2011. 
BRASIL. Casa Civil. Lei $\mathbf{n}^{\circ}$. 6.546, de 4 de julho de 1978. Dispõe sobre a regulamentação das profissões de arquivista e de técnico de arquivo, e dá outras providências. Disponível em: http://www.planalto.gov.br/ccivil 03/leis/1970-1979/16546.htm. Acesso em: 10 mar. 2019.

BRASIL. Casa Civil. Lei $\mathbf{n}^{\circ} \mathbf{. 4 . 0 8 4}$, de 30 de junho de 1962. Dispõe sobre a profissão de bibliotecário e regula seu exercício. Disponível em:

http://www.planalto.gov.br/ccivil 03/LEIS/1950-1969/L4084.htm. Acesso em: 10 mar. 2019.

BRASIL. Casa Civil. Lei $\mathbf{n}^{\circ} \mathbf{7 . 2 8 7}$, de 18 de dezembro de 1984. Dispõe sobre a regulamentação da profissão de museólogo. Disponível em:

http://www.planalto.gov.br/ccivil 03/leis/17287.htm. Acesso em: 10 mar. 2019.

BELLUZZO, R. C. B.; SANTOS, C. A.; ALMEIDA JÚNIOR, O. F. A competência em informação e sua avaliação sob a ótica da mediação da informação: reflexões e aproximações teóricas. Informação \& Informação, Londrina, v. 19, n. 2, p. 60-77, maio/ago. 2014. Disponível em: http://www.uel.br/revistas/uel/index.php/informacao/article/view/19995/pdf 21. Acesso em: 20 set. 2018. DOI: http://dx.doi.org/10.5433/1981-8920.2014v19n2p60.

CAMPOS, C. J. G. Método de análise de conteúdo: ferramenta para a análise de dados qualitativos no campo da saúde. Revista Brasileira de Enfermagem, Brasília, v. 57, n. 5, p. 611614, set./out. 2004. Doi: http://dx.doi.org/10.1590/S0034-71672004000500019.

CAUNE, J. Cultura e comunicação: convergências teóricas e lugares de mediação. São Paulo: UNESP, 2014.

CAUNE, J. La médiation culturelle: une construction du lien social. 2000. Disponível em: http://lesenjeux.u-grenoble3.fr/2000/Caune/Caune.pdf. Acesso em: 20 mar. 2018.

COLOMBIA. Congreso de Colombia. Ley 11, de 5 de março de 1979. Se reconoce la profesión de bibliotecólogo y se reglamenta su ejercicio. Disponível em:

https://www.colciencias.gov.co/sites/default/files/upload/reglamentacion/ley-11-1979.pdf. Acesso em: 20 fev. 2019.

COLOMBIA. Congreso de Colombia. Ley 1409, de 30 de agosto de 2010. Se reglamenta el ejercicio profesional de la Archivística, se dicta el Código de Ética y otras disposiciones. Disponible en:

https://www.usco.edu.co/archivosUsuarios/12/archivo central/NORMATIVIDAD/10.\%20LEY \%201409\%20de\%202010.pdf. Acesso em: 20 abr. 2019.

DUFF, W.; FOX, A. 'You're a guide rather tan an expert': archival reference from an archivist's point of view. Journal of the society of archivists, v. 27, n. 2, p. 129-153, 2006.

GARCÍA CANCLINI, N. Diferentes, desiguales y desconectados: mapas de la interculturalidade. Barcelona: Gedisa, 2004.

JOUËT, J. Pratiques de communication et figures de la médiation: des médias de masse aux technologies de l'information et de la communication. Sociologie de la communication, v. 1, 
n. 1, p. 291-312, 1997. Disponível em: http://www.persee.fr/web/revues/home/\%20prescript/article/reso 0043573021997 mon 11 3843. Acesso em: 20 abr. 2017.

LAVILLE, C.; DIONNE, J. A construção do saber: manual de metodologia da pesquisa em ciências humanas. Belo Horizonte: Editora UFMG, 1999.

MARTÍN-BARBERO, J. Dos meios às mediações. Comunicação, cultura e hegemonia. Rio de Janeiro: UFRJ, 1997.

MORAES, M. B. Mediação, cultura e tecnologia nos currículos dos cursos de ciências da informação na Iberoamérica: repensando um campo científico. 2017. Tese (Doutorado em Cultura e Informação) - Escola de Comunicações e Artes, Universidade de São Paulo, São Paulo, 2017.

OROZCO GÓMEZ, G. Recepción televisiva y mediaciones: la construcción de estrategias por la audiencia. Televidencia: Cuadernos de comunicación y praticas sociales, 6, p. 69-88, 1994.

PARISIER, E. O filtro invisível: o que a internet está escondendo de você. Tradução de Diego Alfaro. Rio de Janeiro: Zahar, 2012.

PIRELA MORILLO, J. Un sistema conceptual sobre los procesos de mediación en las organizaciones de conocimiento en la cibersociedad. Revista Interamericana de Bibliotecología, Medellín, v. 29, n. 1, p. 103-122, ene./jun. 2006. Disponível em:

http://www.scielo.org.co/pdf/rib/v29n1/v29n1a6. Acesso em: 20 jul. 2018.

PIRELA MORILLO, Johann; PULIDO DAZA, Nelson Javier. Actualización curricular del Programa de Sistemas de Información y Documentación de la Universidad de La Salle-Colombia. Investigación Bibliotecológica: archivonomía, bibliotecología e información, Cuidad de México, v. 32, n. 74, p. 145-169, ene./mar. 2018. Disponível em: http://www.scielo.org.mx/scielo.php?pid=S0187-358X2018000100145\&script=sci arttext. Acesso em: 20 mar. 2018.

RASSE, P. La médiation, entre ideal theorique et application pratique. Recherches en communication, Louvain-La-Neuve, n. 13, p. 38-61, 2000.

REIS, A. S.; XAVIER JUNIOR, G. F.; PIRES, H. A. C. O curso de graduação em Biblioteconomia da UFMG. Tendências da Pesquisa Brasileira em Ciência da Informação, [S. I.], v. 4, n. 1, 2011. Disponível em: http://inseer.ibict.br/ancib/index.php/tpbci/article/viewArticle/61. Acesso em: 20 mar. 2016.

RENDÓN ROJAS, M. Á. Conceptualización y fundamentación del Sistema de Información Documental (SID). Códices, Bogotá, v. 9, n. 1, p. 11-20, ene./jun. 2013. Disponible en: http://core.ac.uk/download/pdf/16292299.pdf. Acesso em: 20 abr. 2016.

SANTOS NETO, J. A.; ALMEIDA JÚNIOR, O. F. A disciplina mediação da informação nos currículos dos cursos de Arquivologia, Biblioteconomia e Museologia no Brasil. REBECIN, v. 3, n. 
1, p. 3-23, jan./jun. 2016. Disponível em:

http://www.abecin.org.br/revista/index.php/rebecin. Acesso em: 10 dez. 2018.

VEILLETTE, J. "Quand la culture fait médiation..." Lien social et politiques, Québec, n. 60, p. 105-115, automne, 2008. Disponível em: http://id.erudit.org/iderudit/019449ar. Acesso em: 7 dez. 2010. 